(2) Open Access Full Text Article

ORIGINAL RESEARCH

\title{
Prevalence and pattern of overweight and obesity in three rural communities in southwest Nigeria
}

This article was published in the following Dove Press journal:

Diabetes, Metabolic Syndrome and Obesity:Targets and Therapy

10 May 2014

Number of times this article has been viewed

\author{
Rasaaq A Adebayo' \\ Michael O Balogun' \\ Rufus A Adedoyin² \\ Oluwayemisi A Obashoro- \\ John ${ }^{3}$ \\ Luqman A Bisiriyu ${ }^{4}$ \\ Olugbenga O Abiodun' \\ 'Department of Medicine, \\ ${ }^{2}$ Department of Medical \\ Rehabilitation, Obafemi Awolowo \\ University, lle-Ife, ${ }^{3}$ Department of \\ Adult Education, University of Lagos, \\ Lagos, ${ }^{4}$ Department of Demography \\ and Social Statistics, Obafemi \\ Awolowo University, Ile-Ife, Nigeria
}

Correspondence: Rasaaq A Adebayo Department of Medicine, Obafemi Awolowo University, PO Box 1961, Ile-Ife, Osun State, Nigeria

$\mathrm{Tel}+2348037149610$

Email radebayo@oauife.edu.ng
Background: Limited data exist on the prevalence of overweight and obesity in the Nigerian adult rural population. This study therefore assessed the prevalence and pattern of overweight and obesity in adults in three rural communities of the Ife North Local Government Area, Nigeria.

Materials and methods: A total of 777 adults between 20 and 90 years of age were recruited into this cross-sectional study, which was performed over a 6-month period using a multistage proportional stratified random sampling technique. Sociodemographic data and anthropometric variables were obtained.

Results: A total of 385 (49.5\%) men and 395 (50.5\%) women participated in the study. The mean age and body mass index of the participants were $36.3 \pm 14.3$ years and $23.53 \pm 4.6 \mathrm{~kg} / \mathrm{m}^{2}$, respectively. The overall crude prevalence of overweight and obesity in the total population were $20.8 \%$ and $8.4 \%$, respectively. Obesity increased across the age gradient, peaking in the 51 - to 60 -year age-group in men and women. Among the overweight and obese subjects $(n=227), 70.9 \%$ of them were overweight and the remaining $29.1 \%$ were obese, with class I obesity accounting for $20.7 \%$ of these overweight and obese subjects.

Conclusion: The prevalence of overweight and obesity in these communities was $20.8 \%$ and $8.4 \%$ respectively, indicating a trend towards increased prevalence. Class I obesity is the most common obesity pattern, and obesity increased across the age gradient, peaking in the 51- to 60 -year age-group. There is a need for regular community education on healthy lifestyles, and regular health screening to control the rising prevalence of overweight and obesity, as well as to prevent or reduce the risk of obesity comorbidities in these communities.

Keywords: obesity, prevalence, rural, communities, Osun State, Nigeria

\section{Introduction}

Obesity is associated with an increased risk of multiple health problems and many comorbid conditions, such as cardiovascular diseases, type 2 diabetes, hypertension, certain cancers, and sleep apnea/sleep-disordered breathing. ${ }^{1-4}$ In addition, obesity is becoming a global pandemic, ${ }^{5}$ and there has been an explosive increase in its prevalence worldwide in recent times. ${ }^{6,7}$ This has led to increased morbidity and mortality globally. ${ }^{6,7}$

Cardiovascular diseases produce the greatest morbidity and mortality among these comorbidities, and the greater the obesity, the higher the morbidity and mortality rates. ${ }^{1}$ Cardiovascular diseases that have been associated with obesity include hypertension, heart failure, arrhythmias, ischemic heart disease, obesity-related cardiomyopathy, stroke, and sudden death. ${ }^{5}$ The end result of this is loss of productivity and increased 
burden on health care systems. Altered metabolic profile and changes in the structure and function of the cardiovascular system have been suggested to be responsible for the morbidities seen in obesity. $^{5}$

The development of obesity has been attributed to the combination of environmental and genetic factors. Presently, there over 35 independent genetic risk loci that have been identified for obesity. ${ }^{8}$ The genetic loci regulate eating habits as well as body metabolism and the body's response to exercise and eating. ${ }^{5}$ These loci lead to the development of obesity in environments favorable to it. ${ }^{5}$ Increasing numbers of communities worldwide are becoming favorable to the development of obesity or overweight as a result of dietary changes and sedentary living. The prevalence of obesity is rising in urban adult Nigerians ${ }^{9-11}$ and preschool children, ${ }^{12}$ and mirrors the ongoing global epidemic in children and adults. ${ }^{5}$ In many communities in Nigeria, there are no inbuilt community facilities to encourage regular exercise, and the combination of poverty and poor nutritional education make individuals adopt poor dietary habits.

Some data exist on the prevalence of overweight and obesity among urban and semiurban adult Nigerians. ${ }^{10,11,13-19}$ However, limited information exists on the prevalence of cardiometabolic risk factors, including overweight and obesity, in the adult Nigerian population, especially in the rural setting. ${ }^{20-25}$

This study therefore assessed the prevalence and pattern of overweight and obesity in adult populations living in three rural communities of the Ife North Local Government Area (LGA) of Osun State, southwest Nigeria. This will further help define the prevalence and pattern of overweight and obesity in this rural population, and also add to the national and global database.

\section{Materials and methods}

A total of 777 adults between 20 and 90 years of age from three rural towns of the Ife North LGA of Osun State, southwest Nigeria, were recruited into this cross-sectional study, which was carried out over a 6-month period using a multistage proportional stratified random sampling technique. ${ }^{26}$ The minimum sample size was determined using the formula for calculating sample size in the population, ${ }^{27}$ and the population of the LGA was 153,274 , according to the 2006 population census. ${ }^{28}$ The study procedure followed the World Health Organization (WHO) guidelines for conducting community surveys. ${ }^{29,30}$ The dominant occupation and economic activities of the people of the LGA center around farming, agro-allied productions, trading, artisanship, school administration, teaching, and cottage industries. ${ }^{31}$ There are civil servants in the services of local, state, and federal governments with other corporate and private businesses. The dominant language is Yoruba, and the LGA is the home of Yoruba ethnic group. ${ }^{31}$ The permission of the traditional rulers of each community was sought and informed consent obtained from each participant. The participants' data were collected after community mobilization and consent. The three major towns - Ipetumodu, Edunabon, and Moro - were randomly selected from the seven major towns of Ife North LGA. Ten percent of the census enumeration areas (EAs) were randomly selected from each town which translated to 80 EAs for Ipetumodu, 34 EAs for Edunabon, and 13 EAs for Moro. Six households per EA were randomly selected in Ipetumodu, ten households per EA in Edunabon, and 23 households per EA in Moro. In each household, at least one eligible and consented respondent (aged 20 years and older) was interviewed.

Ethical approval was given by the Ethics and Research Committee of the Obafemi Awolowo University Teaching Hospitals Complex, Ile-Ife. All sociodemographic data were obtained by using a standard questionnaire, and anthropometric variables were measured. ${ }^{32}$ The international classification of adult overweight and obesity according to body mass index (BMI) adapted from the $\mathrm{WHO}^{33}$ was used to define overweight and obesity. Weight was measured in kilograms with a bathroom weighing scale, with subjects standing, arms hanging naturally by the sides, and footwear off. Height was measured using a stadiometer in meters at the crown of the head without any footwear or headgear and the patient looking straight ahead. ${ }^{32}$

Using this classification, ${ }^{33}$ BMI was categorized as follows:

- underweight $=<18.5 \mathrm{~kg} / \mathrm{m}^{2}$

- normal $=\geq 18.5-24.9 \mathrm{~kg} / \mathrm{m}^{2}$

- $\quad$ overweight $=25-29.9 \mathrm{~kg} / \mathrm{m}^{2}$

- $\quad$ class I obesity $=30-34.9 \mathrm{~kg} / \mathrm{m}^{2}$

- $\quad$ class II obesity $=35-39.9 \mathrm{~kg} / \mathrm{m}^{2}$

- class III (commonly called severe or morbid obesity) $=\geq 40 \mathrm{~kg} / \mathrm{m}^{2}$

Table I Characteristics of the subjects $(n=777)$

\begin{tabular}{lllc}
\hline & Minimum & Maximum & Mean \pm SD \\
\hline Age, years & 21 & 90 & $36.3 \pm 14.3$ \\
Height, m & 1.20 & 1.90 & $1.6 \pm 0.1$ \\
Weight, kg & 32 & 128 & $63.4 \pm 12.2$ \\
Waist circumference, cm & 32 & 140 & $81.0 \pm 12.2$ \\
Hip circumference, cm & 38 & 152 & $92.4 \pm 13.3$ \\
BMl, kg/m & 12.9 & 50.0 & $23.5 \pm 4.6$ \\
\hline
\end{tabular}

Abbreviations: SD, standard deviation; BMI, body mass index. 
Table 2 Differences in results between males and females $(n=777)$

\begin{tabular}{llll}
\hline & $\begin{array}{l}\text { Male }(\mathbf{n}=382), \\
\text { mean } \pm \text { SD }\end{array}$ & $\begin{array}{l}\text { Female }(\mathbf{n = 3 9 5 )} \\
\text { mean } \pm \text { SD }\end{array}$ & P-value \\
\hline Age, years & $35.7 \pm 13.4$ & $36.9 \pm 15.2$ & 0.269 \\
Height, $\mathrm{m}$ & $1.66 \pm 0.1$ & $1.64 \pm 0.1$ & $0.002^{* *}$ \\
Weight, $\mathrm{kg}$ & $65.2 \pm 11.9$ & $62.1 \pm 12.3$ & $0.000^{* *}$ \\
Waist & $82.1 \pm 12.3$ & $80.0 \pm 12.1$ & $0.020^{*}$ \\
circumference, cm & & & \\
Hip circumference, cm & $93.4 \pm 12.5$ & $91.4 \pm 14.0$ & $0.038^{*}$ \\
BMI, $\mathrm{kg} / \mathrm{m}^{2}$ & $23.8 \pm 4.6$ & $23.2 \pm 4.6$ & 0.287 \\
\hline
\end{tabular}

Notes: $* * P<0.001 ; * P<0.05$.

Abbreviations: SD, standard deviation; BMI, body mass index.

Waist circumferences (WC) and hip circumference (HC) were also measured according to the $\mathrm{WHO}$ protocol. ${ }^{30,34} \mathrm{WC}$ values $\geq 102 \mathrm{~cm}$ for males and $\geq 88 \mathrm{~cm}$ for females were regarded as abdominal obesity. ${ }^{24}$

\section{Data analysis}

The data were summarized using descriptive statistics (mean, standard deviations, and percentages). Independent $t$-tests were used to compare the age and physical characteristics of males and females. Significant differences of values of variables across the age-groups were determined by analysis of variance. Multiple comparisons between the groups were performed by one-way analysis of variance with Duncan's post hoc test. $P \leq 0.05$ was considered statistically significant. The data were analyzed using SPSS 16 (SPSS, Chicago, IL, USA) software.

\section{Results}

A total of 777 adults participated in the study (385 [49.5\%] men and 395 [50.5\%] women), as shown in Table 1. The mean age and BMI of the participants were $36.3 \pm 14.3$ years and $23.53 \pm 4.6 \mathrm{~kg} / \mathrm{m}^{2}$, respectively. The mean BMI for males and females was $23.8 \pm 4.6 \mathrm{~kg} / \mathrm{m}^{2}$ and $23.2 \pm 4.6 \mathrm{~kg} / \mathrm{m}^{2}$, respectively, as shown in Table 2 . The overall crude prevalence of overweight and obesity in the total population was $20.8 \%$ and $8.4 \%$, respectively. Obesity using BMI increased across the age gradient, peaking in the 51- to 60-year age-group in men and women (Table 3). Mean WC and HC also increased across the age gradient, peaking in the 51 to 60 -year agegroup in the total population (Table 4). Among the overweight and obese subjects ( $\mathrm{n}=227), 70.9 \%$ of them were overweight and the remaining $29.1 \%$ were obese (Table 5). Class I obesity was the most common obesity pattern, accounting for $20.7 \%$ among these overweight and obese subjects (Table 5), $71.4 \%$ of the obese subjects, and $6 \%$ of the total study population (Table 3).

\section{Discussion}

The prevalence of overweight and obesity in these three rural communities of $20.8 \%$ and $8.4 \%$, respectively, is less than the prevalence rates of overweight and obesity of $32.7 \%$ and $22.2 \%$ in an urban community in southwest Nigeria, ${ }^{35} 35.1 \%$ and $9.8 \%$ in north-central Nigeria, ${ }^{36}$ and $23.4 \%$ and $17.1 \%$ by Amoah in Ghana, ${ }^{37}$ respectively. This finding thus corroborates earlier studies that observed a higher prevalence of obesity and/or overweight in urban and semiurban populations compared with rural populations in Africa. ${ }^{10,11,13,15,17,20,38-41}$

Therefore, the prevalence of obesity in these rural communities is less than the $12.5 \%$ we obtained in the neighboring semiurban community in Ile-Ife, ${ }^{11}$ the $21.3 \%$ obtained

Table 3 Percentage distribution of body mass index by age and sex

\begin{tabular}{|c|c|c|c|c|c|c|c|}
\hline \multirow{2}{*}{$\begin{array}{l}\text { Sex and age-groups } \\
\text { (years) }\end{array}$} & \multirow{2}{*}{$\mathrm{n}$} & \multicolumn{6}{|c|}{ Distribution of subjects' body mass index (\%) } \\
\hline & & $<18.49 \mathrm{~kg} / \mathrm{m}^{2}$ & $18.5-24.9 \mathrm{~kg} / \mathrm{m}^{2}$ & $25.0-29.9 \mathrm{~kg} / \mathrm{m}^{2}$ & $30.0-34.9 \mathrm{~kg} / \mathrm{m}^{2}$ & $35.0-39.9 \mathrm{~kg} / \mathrm{m}^{2}$ & $>40.0 \mathrm{~kg} / \mathrm{m}^{2}$ \\
\hline \multicolumn{8}{|l|}{ Men } \\
\hline $21-30$ & 193 & 8.3 & 65.3 & 21.2 & 4.1 & 1.0 & - \\
\hline $31-40$ & 90 & 6.7 & 57.8 & 23.3 & 8.9 & - & 3.3 \\
\hline $4 I-50$ & 43 & 11.6 & 51.2 & 23.3 & 11.6 & 2.3 & - \\
\hline $51-60$ & 37 & 5.4 & 35.1 & 29.7 & 21.6 & 8.1 & - \\
\hline $61+$ & 19 & 21.1 & 63.2 & 10.5 & 5.3 & - & - \\
\hline All men & 382 & 8.6 & 58.9 & 22.3 & 7.9 & 1.6 & 0.8 \\
\hline \multicolumn{8}{|l|}{ Women } \\
\hline $21-30$ & 190 & 7.9 & 68.9 & 18.9 & 2.6 & 0.5 & I.I \\
\hline $31-40$ & 95 & 6.3 & 64.2 & 18.9 & 5.3 & 2.1 & 3.2 \\
\hline $4 I-50$ & 46 & 15.2 & 54.3 & 21.7 & 4.3 & 4.3 & - \\
\hline $5 I-60$ & 24 & 12.5 & 54.2 & 20.8 & 12.5 & - & - \\
\hline $61+$ & 40 & 12.5 & 67.5 & 15.0 & 5.0 & - & - \\
\hline All women & 395 & 9.1 & 65.1 & 19.0 & 4.3 & 1.3 & 1.3 \\
\hline Total & 777 & 8.9 & 61.9 & 20.8 & 6.0 & 1.4 & 1.0 \\
\hline
\end{tabular}


Table 4 Values of WC and HC across age-groups ( $n=777)$

\begin{tabular}{|c|c|c|c|}
\hline \multirow[t]{2}{*}{ Age-group } & \multirow[t]{2}{*}{$\mathbf{n}$} & \multirow{2}{*}{$\frac{W C(\mathrm{~cm})}{\text { Mean } \pm \text { SD }}$} & \multirow{2}{*}{$\frac{\mathrm{HC}(\mathrm{cm})}{\text { Mean } \pm \mathrm{SD}}$} \\
\hline & & & \\
\hline $21-30$ years & 383 & $77.7 \pm 9.2^{\mathrm{a}}$ & $90.4 \pm 10.8^{a}$ \\
\hline $31-40$ years & 185 & $82.9 \pm 14.6^{b}$ & $94.5 \pm 16.3^{b, c}$ \\
\hline $4 I-50$ years & 89 & $84.4 \pm \mid 2 . I^{b, c}$ & $94.2 \pm 13.0^{\mathrm{a}-\mathrm{c}}$ \\
\hline $5 I-60$ years & 61 & $87.1 \pm 15.4^{c}$ & $96.3 \pm 16.3^{c}$ \\
\hline $61+$ years & 59 & $85.3 \pm 12.1^{b, c}$ & $91.6 \pm 12.8^{\mathrm{a}, \mathrm{b}}$ \\
\hline Total & 777 & $81.0 \pm 12.2$ & $92.4 \pm 13.2$ \\
\hline$P$-value & & 0.000 & 0.000 \\
\hline
\end{tabular}

Notes: ${ }^{a-c}$ Using Duncan's post hoc test, group a is different from b, and b from c. Abbreviations: SD, standard deviation; WC, waist circumference; HC, hip circumference.

by Sani et al in an urban community in Katsina, northern Nigeria, ${ }^{15}$ and the $8.82 \%$ by Olatunbosun et al obtained in an urban community in Ibadan, southwest Nigeria. ${ }^{10}$ Oyeyemi et a ${ }^{38}$ also obtained a overweight prevalence of $22.8 \%$ among urban adults in Maiduguri, northern Nigeria, higher than the prevalence of $20.8 \%$ in this study.

In addition, Adediran et $a l,{ }^{13}$ in their recent study of anthropometric differences among natives of Abuja, Nigeria living in urban and rural communities, found that all anthropometric indices of overweight and obesity considered in their study were significantly higher in the urban than in the rural population. Overweight and obesity were significantly prevalent among their urban population. ${ }^{13} \mathrm{Ntandou}$ et al in the Republic of Benin also showed a positive rural-urban gradient in the prevalence of abdominal obesity ${ }^{40}$ and mean BMI in this study was lower than that reported among adults in an urban area of Abuja, Nigeria ${ }^{39}$ and US blacks. ${ }^{41}$ It has been suggested that better nutrition and increased physical activity are responsible for this positive rural-urban gradient. ${ }^{40}$

Mean WC and HC increased with age, and peaked in the 51- to 60-year age-group. Mean BMI increased with age in both sexes, and peaked in the 51- to 60-year age-group in males and females. This peak is similar to the findings of Adediran et $\mathrm{al}^{39}$ in Abuja, who found the peak in the 50- to 59-year age-group in both sexes.

Earlier reports indicated that the prevalence of obesity in the rural population in Nigeria is relatively low. For example,

Table 5 Prevalence of overweight and obesity of all participants by sex

\begin{tabular}{llll}
\hline Prevalence & $\begin{array}{l}\text { Male } \\
(\mathbf{n = 1 2 5 )}\end{array}$ & $\begin{array}{l}\text { Female } \\
(\mathbf{n}=102)\end{array}$ & $\begin{array}{l}\text { Total population } \\
(\mathbf{n}=\mathbf{2 2 7})\end{array}$ \\
\hline Overweight (\%) & 68.8 & 73.5 & 70.9 \\
Class I obesity (\%) & 24.0 & 16.7 & 20.7 \\
Class II obesity (\%) & 4.8 & 4.9 & 4.8 \\
Class III obesity (\%) & 2.4 & 4.9 & 3.5 \\
\hline
\end{tabular}

Okesina et $\mathrm{al}^{23}$ in 1999 reported obesity prevalence of $2 \%$ in three rural villages around Maiduguri in northeastern Nigeria. However, recent prevalence reports indicated that the prevalence is increasing, and they confirmed our finding of increased prevalence of overweight and obesity in this rural adult Nigerian population. ${ }^{14,18,20,21,24} \mathrm{Iloh}$ et al ${ }^{25}$ also reported a high prevalence of obesity among rural adult Nigerians in Imo State, southeastern Nigeria, of $6.0 \%$. They also found that class I obesity $(86.1 \%)$ was the most common pattern among this rural population, which supported our finding that class I obesity (71.4\%) was the most common obesity pattern in our obese subjects.

This study finding of increased prevalence of overweight and obesity in the rural adult Nigerian population, supported by other recent reports, ${ }^{14,18,20,21,24,25}$ should alert the health authorities at all levels of government and community leaders on the need to include the prevention and control of overweight and obesity as well as the risk of obesity comorbidities in the planning of health services for these rural communities. There should be regular community education on lifestyle modification, and regular health screening to facilitate the early detection of overweight and obesity, as well as the institution of appropriate preventive and therapeutic measures. ${ }^{20,25}$

\section{Conclusion}

The prevalence of overweight and obesity in the three rural communities was $20.8 \%$ and $8.4 \%$ respectively, indicating a trend towards increased prevalence. Class I obesity is the most common obesity pattern, and obesity increased across the age gradient, peaking in the 51 to 60 -year age-group in both men and women. There is a need for regular community education on healthy lifestyles, and regular health screening to control the rising prevalence of overweight and obesity, as well as to prevent or reduce the risk of obesity comorbidities in these communities.

\section{Acknowledgment}

This project was funded by a grant given jointly by the US Centers for Diseases Control and the Prevention and International Union for Health Promotion and Education, France.

\section{Disclosure}

The authors report no conflicts of interest in this work.

\section{References}

1. Akintunde AA, Akinwusi PO, Adebayo RA, Ogunyemi S, Opadijo OG. Burden of obesity in essential hypertension: pattern and prevalence. Niger J Clin Pract. 2010;13(4):399-402. 
2. González-Zapata LI, Deossa GC, Monsalve-Álvarez J, Díaz-García J, Babio N, Salas-Salvadó J. Metabolic syndrome in healthcare personnel of the University of Antioquia-Colombia; LATINMETS study. Nutr Hosp. 2013;28(2):522-531.

3. Vucenik I, Stains JP. Obesity and cancer risk: evidence, mechanisms, and recommendations. Ann NY Acad Sci. 2012;1271:37-43.

4. Leinum CJ, Dopp JM, Morgan BJ. Sleep-disordered breathing and obesity: pathophysiology, complications, and treatment. Nutr Clin Pract. 2009;24(6):675-687.

5. Poirier P, Giles TD, Bray GA, et al. Obesity and cardiovascular disease: pathophysiology, evaluation, and effect of weight loss: an update of the 1997 American Heart Association Scientific Statement on Obesity and Heart Disease from the Obesity Committee of the Council on Nutrition, Physical Activity, and Metabolism. Circulation. 2006;113(6): 898-918.

6. Engeland A, Bjørge T, Søgaard AJ, Tverdal A. Body mass index in adolescence in relation to total mortality: 32-year follow-up of 227,000 Norwegian boys and girls. Am J Epidemiol. 2003;157(6):517-523.

7. Flegal KM, Carroll MD, Ogden CL, Johnson CL. Prevalence and trends in obesity among US adults, 1999-2000. JAMA. 2002;288(14): $1723-1727$.

8. Li X, Liang L, Zhang M, et al. Obesity-related genetic variants, human pigmentation, and risk of melanoma. Hum Genet 2013;132(7):793-801.

9. Chukwuonye II, Chuku A, John C, et al. Prevalence of overweight and obesity in adult Nigerians - a systematic review. Diabetes Metab Syndr Obes. 2013;6:43-47.

10. Olatunbosun ST, Kaufman JS, Bella AF. Prevalence of obesity and overweight in urban adult Nigerians. Obes Rev. 2011;12(4):233-241.

11. Adedoyin RA, Mbada CE, Balogun MO, Adebayo RA, Martins T, Ismail S. Obesity prevalence in adult residents of Ile-Ife, Nigeria. Nig Q J Hosp Med. 2009;19(1):63-68.

12. Senbanjo IO, Adejuyigbe EA. Prevalence of overweight and obesity in Nigerian preschool children. Nutr Health. 2007;18(4):391-399.

13. Adediran OS, Adebayo PB, Akintunde AA. Anthropometric differences among natives of Abuja living in urban and rural communities: correlations with other cardiovascular risk factors. BMC Res Notes. 2013;6:123.

14. Hendriks ME, Wit FW, Roos MT, et al. Hypertension in sub-Saharan Africa: cross-sectional surveys in four rural and urban communities. PLoS One. 2012;7(3):e32638.

15. Sani MU, Wahab KW, Yusuf BO, Gbadamosi M, Johnson OV, Gbadamosi A. Modifiable cardiovascular risk factors among apparently healthy adult Nigerian population - a cross sectional study. BMC Res Notes. 2010;3:11.

16. Lawoyin TO, Asuzu MC, Kaufman J, et al. Prevalence of cardiovascular risk factors in an African, urban inner city community. West Afr J Med. 2002;21(3):208-211.

17. Abubakar AR, Bhopal RS. Systematic review on the prevalence of diabetes, overweight/obesity and physical inactivity in Ghanaians and Nigerians. Public Health. 2008;122(2):173-182.

18. Sola AO, Steven AO, Kayode JA, Olayinka AO. Underweight, overweight and obesity in adults Nigerians living in rural and urban communities of Benue State. Ann Afr Med. 2011;10(2):139-143.

19. Ezenwaka CE, Akanji AO, Akanji BO, Unwin NC, Adejuwon CA. The prevalence of insulin resistance and other cardiovascular disease risk factors in healthy elderly southwestern Nigerians. Atherosclerosis. 1997;128(2):201-211.

20. Oladapo OO, Salako L, Sodiq O, Shoyinka K, Adedapo K, Falase AO. A prevalence of cardiometabolic risk factors among a rural Yoruba south-western Nigerian population: a population-based survey. Cardiovasc J Afr. 2010;21(1):26-31.
21. Ejim EC, Okafor CI, Emehel A, et al. Prevalence of cardiovascular risk factors in the middle-aged and elderly population of a Nigerian rural community. J Trop Med. 2011;2011:308687.

22. Adegoke OA, Adedoyin RA, Balogun MO, Adebayo RA, Bisiriyu LA, Salawu AA. Prevalence of metabolic syndrome in a rural community in Nigeria. Metab Syndr Relat Disord. 2010;8(1):59-62.

23. Okesina AB, Oparinde DP, Akindoyin KA, Erasmus RT. Prevalence of some risk factors of coronary heart disease in a rural Nigerian population. East Afr Med J. 1999;76(4):212-216.

24. Ahaneku GI, Osuji CU, Anisiuba BC, Ikeh VO, Oguejiofor OC, Ahaneku JE. Evaluation of blood pressure and indices of obesity in a typical rural community in eastern Nigeria. Ann Afr Med. 2011;10(2): 120-126.

25. Iloh G, Amadi AN, Nwankwo BO, Ugwu VC. Obesity in adult Nigerians: a study of its pattern and common primary co-morbidities in a rural Mission General Hospital in Imo state, South-Eastern Nigeria. Niger J Clin Pract. 2011;14(2):212-218.

26. Nworgu BG. Educational Research: Basic Issues and Methodology. Ibadan, Nigeria: Wisdom; 2006

27. Abramson JH, Gahlinger PM. Computer Programs for Epidemiologists. PEPI Version 3.01. Llanidhoes, Wales: Brixton Books; 1999.

28. Nigeria National Population Commission. Population Distribution by Sex, State, LGA and Senatorial District. Vol III. Available from: http:// www.population.gov.ng/images/Vol\%2003\%20Table\%20DSx $\% 20$ LGAPop\%20by\%20SDistrict-PDF.pdf. Accessed July 30, 2013.

29. World Health Organization. Guidelines for Conducting Community Surveys on Injuries and Violence. Geneva: WHO; 2004.

30. World Health Organization. WHO STEPS Surveillance Manual: The WHO STEP wise Approach to Chronic Disease Risk Factor Surveillance (STEPS). Geneva: WHO; 2005.

31. Omoworare B. Osun East Senatorial District of Osun State Nigeria. 2011. Available from: http://www.babajideomoworare.com/district. html. Accessed January 30, 2014.

32. Adedoyin RA, Mbada CE, Bisiriyu LA, Adebayo RA, Balogun MO, Akintomide AO. Relationship of anthropometric indicators with blood pressure levels and the risk of hypertension in Nigerian adults. Int $J$ Gen Med. 2008;1:33-40.

33. World Health Organization. Obesity: Preventing and Managing the Global Epidemic. Geneva: WHO; 2000.

34. World Health Organization. Waist Circumference and Waist-Hip Ratio: Report of a WHO Expert Consultation, Geneva, December 8-11, 2008. Geneva: WHO; 2008.

35. Amira CO, Sokunbi DO, Dolapo D, Sokunbi A. Prevalence of obesity, overweight and proteinuria in an urban community in South West Nigeria. Niger Med J. 2011;52(2):110-113.

36. Desalu OO, Salami AK, Oluboyo PO, Olarinoye JK. Prevalence and socio-demographic determinants of obesity among adults in an urban Nigerian population. Sahel Med J. 2008;11(2):61-64.

37. Amoah AG. Sociodemographic variations in obesity among Ghanaian adults. Public Health Nutr. 2003;6(8):751-757.

38. Oyeyemi AL, Adegoke BO, Oyeyemi AY, Deforche B, De Bourdeaudhuij I, Sallis JF. Environmental factors associated with overweight among adults in Nigeria. Int J Behav Nutr Phys Act. 2012;9:32.

39. Adediran OS, Okpara IC, Adeniyi OS, Jimoh AK. Obesity prevalence and its associated factors in an urban and rural area of Abuja Nigeria. Glob Adv Res J Med Med Sci. 2012;1(8):237-241.

40. Ntandou G, Delisle H, Agueh V, Fayomi B. Abdominal obesity explains the positive rural-urban gradient in the prevalence of the metabolic syndrome in Benin, West Africa. Nutr Res. 2009;29(3):180-189.

41. Ogden CL, Carroll MD, Curtin LR, McDowell MA, Tabak CJ, Flegal KM. Prevalence of overweight and obesity in the United States, 1999-2004. JAMA. 2006;295(13):1549-1555. 


\section{Publish your work in this journal}

Diabetes, Metabolic Syndrome and Obesity: Targets and Therapy is opinion and commentaries are all considered for publication. The an international, peer-reviewed open-access journal committed to the rapid publication of the latest laboratory and clinical findings in the fields of diabetes, metabolic syndrome and obesity research. Original research, review, case reports, hypothesis formation, expert manuscript management system is completely online and includes a very quick and fair peer-review system, which is all easy to use. Visit http://www.dovepress.com/testimonials.php to read real quotes from published authors.

Submit your manuscript here: http://www.dovepress.com/diabetes-metabolic-syndrome-and-obesity-targets-and-therapy-journal 